\title{
Susanne Zwirlein
}

\section{Versprechen und Zufall}

Eine historisch-vergleichende Studie zur Gefahrtragung beim Kauf beweglicher Sachen im englischen und deutschen Recht

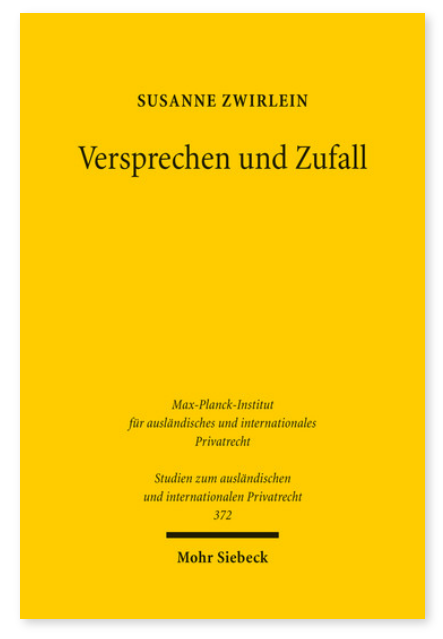

2017. XIII, 331 Seiten. StudIPR 372

ISBN 978-3-16-155238-0

DOI 10.1628/978-3-16-155238-0

eBook PDF 79,00€

ISBN 978-3-16-155136-9

fadengeheftete Broschur 79,00€
Inwieweit sind Vertragsparteien an ihre Versprechen gebunden, obwohl der Zufall ihre Pläne durchkreuzt hat? Diese Frage nach der Gefahrtragung zielt auf Grundprobleme des Vertragsrechts. Susanne Zwirlein analysiert die Genese der Regeln zu Unmöglichkeit und Gefahrtragung beim Kauf beweglicher Sachen im englischen und deutschen Recht in ihrem ideengeschichtlichen Kontext. Flankierend unternimmt sie einen kritischen Ausblick auf Möglichkeiten und Grenzen einer Rechtsvereinheitlichung auf diesem Gebiet. Sie zeigt auf, welche erheblichen Unterschiede die historische Entwicklung und die dogmatischen Tiefenstrukturen von Unmöglichkeit und Gefahrtragung im englischen und deutschen Recht aufweisen. Die Verfasserin gewinnt ihre Ergebnisse durch eine historisch-vergleichende Analyse, die Quellen von der Antike bis in die Gegenwart umfasst.

Susanne Zwirlein Geboren 1989; Studium der Rechtswissenschaft in München und Oxford; Referendariat am Landgericht München I; wissenschaftliche Mitarbeiterin am Lehrstuhl für Bürgerliches Recht, Internationales Privatrecht und Rechtsvergleichung an der Ludwig-Maximilians-Universität München; 2016 Promotion; seit 2016 Rechtsanwältin in München und Lehrbeauftragte an der Ludwig-Maximilians-Universität München.
Jetzt bestellen:

https://mohrsiebeck.com/buch/versprechen-und-zufall-9783161552380?no_cache=1

order@mohrsiebeck.com

Telefon: +49 (0)7071-923-17

Telefax: +49 (0)7071-51104 